\title{
Product variety and technical change
}

\author{
Richard Frensch ${ }^{\mathrm{a}}$ and Vitalija Gaucaite-Wittich ${ }^{\mathrm{b}}$
}

this version: October 2006

Abstract: Several trade-based measures of product variety have recently been used implicitly to represent states of technology, promoting long-run growth. In this paper, we define the state of technology as the range of specialised production processes and propose the variety of capital goods available for production as a direct measure of technology. Within a simple growth framework, we derive a testable "conditional technological convergence" hypothesis on this measure. The hypothesis is tested with highly disaggregated trade data by economic categories, using tools from the income convergence literature. The results suggest that trade-based count measures of the variety of available capital goods indeed behave "as if" they were representing technology and that there is conditional technological convergence among our panel of mainly OECD and transition economies.

JEL-Classification: F14, O33

Keywords: Product variety, diffusion, adoption, technical change

\footnotetext{
${ }^{\text {a }}$ Corresponding author. Department of Economics, Osteuropa-Institut München, Scheinerstr. 11, 81679 München, Germany. Email: frensch@oei-muenchen.de

b Statistics Division, Economic Commission for Europe, United Nations, Palais des Nations, 1211 Genève 10, Switzerland. Email: Vitalia.Gaucaite@unece.org

We are grateful to Daryll Rhoades and Ludmila Sedlmajer of the UNECE Statistics Division for excellent help with the data. Vania Etropolska and Birgit Schwarz provided valuable research assistance. Comments from Laura Altinger, Fabrizio Carmignani, Jaromir Cekota, Rumen Dobrinsky, Michael Funke, Dieter M. Hesse, Veronika Movchan, Handan del Pozzo, Johannnes Stephan, and Volkhart Vincentz, as well as seminar participants in Freiberg, Munich and Regensburg are gratefully appreciated. Richard Frensch acknowledges financial assistance from a Bavarian Ministry of Science forost grant.
} 


\section{Product variety and technical change}

Abstract: Several trade-based measures of product variety have recently been used implicitly to represent states of technology, promoting long-run growth. In this paper, we define the state of technology as the range of specialised production processes and propose the variety of capital goods available for production as a direct measure of technology. Within a simple growth framework, we derive a testable "conditional technological convergence" hypothesis on this measure. The hypothesis is tested with highly disaggregated trade data by economic categories, using tools from the income convergence literature. The results suggest that trade-based count measures of the variety of available capital goods indeed behave "as if" they were representing technology and that there is conditional technological convergence among our panel of mainly OECD and transition economies.

JEL-Classification: F14, O33

Keywords: Product variety, diffusion, adoption, technical change 


\section{Introduction: product variety as a potential measure of technology}

New theories of growth emphasise ideas as the basis of innovative activity. As ideas are non-rival and partially excludable, innovations, by tying ideas to new products or processes, obey increasing returns to scale (Romer, 1990). When introducing this concept into a monopolistic competition model, technical progress is reflected in a higher variety of intermediate capital goods, and is thus embedded in a deepening division of labour, as already illustrated in Adam Smith's example of the making of pins.

In spite of the advances of theories of growth, there has so far been little reflection of this insight in empirical attempts at measuring technical change. In a recent overview, Keller (2004, p. 757) does not mention product variety as a potential measure of technology but rather holds that "technology is an intangible that is difficult to measure directly. Three widely used indirect approaches are to measure (1) inputs (R\&D), (2) outputs (patents), and (3) the effect of technology (higher productivity)."

The productivity-increasing property of more product variety has, however, recently been exploited in attempts to relate levels or growth rates of productivity to several measures of variety. The results suggest that across OECD and selected east European countries one can find trade-based measures of variety, which - together with physical investment - are significant for explaining variations in per capita income levels, ${ }^{1}$ and contribute to differences in productivity growth. ${ }^{2}$

Of the very few existing attempts to empirically account for observable degrees of product variety, only Addison (2003) does so within a framework of technology diffusion and adoption: ${ }^{3}$ according to his study, the introduction of new export items in countries with already very high levels of export variety appears to be driven by

\footnotetext{
${ }^{1}$ See Funke and Ruhwedel (2001 and 2005) and this paper's authors' earlier work in UNECE (2004).

${ }^{2}$ This has been shown to be the case for the productivity lead of South Korea over Taiwan (Feenstra et al., 1999). Addison (2003) has recently suggested that a relationship between the variety of exported industrial goods and total factor productivity might also hold in terms of growth rates across a sample of 29 developed and developing countries.

${ }^{3}$ Other approaches are based on static models of international trade. In this case, for a given technology, increasing returns to scale and a preference for variety lead to variety measures being explained by country size (i.e. GDP or employment). Measures of export variety have been found to be correlated with country size, see Hummels and Klenow (2005).
} 
R\&D. In contrast, countries that are furthest away from the frontier of export variety tend to experience the highest variety growth rates, which lends support to the existence of a diffusion process, where a combined effect of educational attainment and the original variety gap increases the growth rates of export variety in developing countries.

While the existing studies rather indiscriminately apply trade-based measures of variety - mostly in terms of all exported goods -, no study has so far consistently attempted to empirically account for product variety strictly within a framework consistent with modern theories of growth. This paper fills this gap by interpreting the division of labour, expressed as the variety of capital goods available for production as a direct measure of the state of technology. The rest of the paper is organised as follows: section 2 derives a testable "conditional technological convergence" hypothesis on product variety from a simple framework consistent with modern theories of growth. Section 3 introduces our unique database of highly disaggregated trade-based product variety measures by economic categories, allowing for product differentiation by country of origin, and illustrates some stylised facts about product variety across the countries covered. In section 4 , we test the conditional technological convergence hypothesis using tools from the income convergence literature. Section 5 concludes.

\section{A testable hypothesis on the variety of available capital goods}

\subsection{Theoretical framework}

Our starting point is a simple augmented Solow model of growth and development. ${ }^{4}$ Innovations increase the variety of intermediate capital goods, which are diffused across countries depending upon their absorptive capacities. Output $Y$ is produced by labour, $L$, and a variety of intermediate capital goods, $x_{j}$, according to

$$
Y=L^{1-\alpha} \int_{0}^{h} x_{j}^{\alpha} d j
$$

\footnotetext{
${ }^{4}$ Section 2.1 is based on chapter 6 of Jones (2002).
} 
neglecting the time dimension for the moment. The range or variety of capital goods, $h$, is an important parameter of the technology of production in the Smithian sense of the division of labour. As long as one unit of an intermediate capital good can be produced effortlessly from one unit of raw capital, $K$, and assuming that all intermediate capital goods are priced equally, then $x_{j}=x$ for all $j$ and the aggregate production function is of the familiar form

$$
Y=K^{\alpha}(h L)^{1-\alpha}
$$

illustrating the labour-augmenting character of the technology parameter $h$. Explicitly introducing the time dimension, physical capital accumulation follows the standard form,

$$
\dot{K}=s_{k} Y_{t}-d K_{t},
$$

where $s_{k}$ is the rate of investment and $d$ denotes the rate of depreciation of physical capital.

More interesting for our purposes, however, is the development of the variety of intermediate capital goods, $h$, over time. Here, we assume that the variety of capital goods, which the labour force can work with, is limited by their human capital. This is in the spirit of theoretical approaches such as Keller's (1996) formalisation of “absorptive capacity", going back to Nelson and Phelps (1966), or Basu and Weil's (1998) concept of an "appropriate technology." Both stress the idea that a firm or a country, in order to be able to successfully adopt new technologies, needs to have certain skills.

Specifically, suppose that individuals in a country learn to use more capital goods according to the geometrically weighted average of the technological frontier, $A$, and the country's technology, $h$, and according to their own human capital,

$$
\dot{h}_{t}=\mu e^{\psi u} A_{t}^{\gamma} h_{t}^{1-\gamma}, \mu>0 \text { and } 0 \leq \gamma \leq 1
$$

which in fact reproduces equation (6.4) in Jones (2002, p. 126) and goes back as far as Nelson and Phelps (1966). $u$ denotes the time spent accumulating skills instead of working; $\psi$ denotes the returns to schooling, in terms of the percentage of income 
gained by an additional year of schooling; $\mu$ refers to the efficiency of human capital formation, and may subsume the influences on absorptive capacities other than human capital..$^{5} A$ denotes the world technology frontier, i.e. the variety of capital goods available in the world economy. In line with the evidence, we assume that this variety increases over time due to innovations in the very few most advanced economies in the world. ${ }^{6}$ In consequence, the adoption of innovations, channelled by trade, FDI, and patenting, is the dominant source of change in available technology in most of the world, and thus of productivity gains and growth, and we assume even more strictly that the technology frontier expands at a constant rate, $g$.

Re-writing (3) in terms of the growth rate of $h$, and defining $B_{t}=h_{t} / A_{t}$ as the variety of capital goods available in a country relative to the world technology frontier,

$$
\frac{\dot{h}_{t}}{h_{t}}=\mu e^{\psi u} B_{t}^{-\gamma},
$$

such that moving towards the technology frontier slows down the speed of technological catch-up.

Technology gap concepts such as (4), based on Gerschenkron's (1952) notion of the advantage of backwardness, are highly popular in empirical approaches dealing with diffusion and adoption. In particular, a number of studies take (4) as the direct point of departure for econometric specification, often hypothesising "combined effects" between human capital endowment and a measure of initial relative technology on the speed of diffusion (inter alia Nelson and Phelps, 1966; Griffith et al. 2000; Addison, 2003).

Rather than following the "combined effects" avenue, in the following section, we derive an empirically testable hypothesis from (4) that has the advantage that it clearly separates the various influences on our proposed direct measure of technology, i.e. the variety of capital goods available for production. This will be done strictly in

\footnotetext{
${ }^{5}$ The empirical evidence recently presented in Keller (2004) and Comin and Hobijn (2004) suggests that the most important determinants of the speed at which a country adopts technologies are its human capital endowment and $R \& D$ expenditures but also the quality of public governance and the degree of openness to trade.
} 
accordance with the growth context above and analogously to the derivation of testable hypotheses on income convergence.

In the economy (1) - (3), $s_{k}$, $u$, the growth rate of the labour force, $n$, and the rate of expansion of the technology frontier, $g$, are all exogenous and constant. From (2), we know that $h$ is labour augmenting so that the growth rate of $h$ will determine the growth rates of physical capital per worker and output per worker. Thus, the growth rate of $h$ needs to be constant in the steady state. According to (4), this requires $B_{t}$ to be constant such that $A_{t}$ and $h_{t}$ must grow at the same rate, i.e. $g_{h}=g_{A}=g$. ${ }^{7}$ Therefore, along the steady-state growth path,

$$
B^{*}=\left(\frac{\mu}{g} e^{\psi u}\right)^{\frac{1}{\gamma}}
$$

where $\mu$ can be scaled down to be sufficiently small to ensure that $B^{*}<1$.

\subsection{Conditional convergence of states of technology}

In order to study the dynamic behaviour of a country's technology, $h_{t}$, relative to the frontier, $A_{t}{ }^{8}$ we log-linearise (4) in $B_{t}$ around the steady state $B^{*}$, to arrive at

$$
\begin{aligned}
\delta_{h(t)}=\frac{\dot{h}_{t}}{h_{t}} & \approx \mu e^{\psi \nu}\left[e^{-\gamma \ln B^{*}}-\gamma e^{-\gamma \ln B^{*}}\left(\ln B_{t}-\ln B^{*}\right)\right] \\
& =\mu e^{\psi u} e^{-\gamma \ln B^{*}}\left[1+\gamma\left(\ln B^{*}-\ln B_{t}\right)\right] \\
& =\mu e^{\psi u}\left(B^{*}\right)^{-\gamma}\left[1+\gamma\left(\ln B^{*}-\ln B_{t}\right)\right]
\end{aligned}
$$

From the definition of the steady state in (5), this implies

\footnotetext{
${ }^{6}$ While their share in world GDP was already 64 per cent in 1995, the seven largest industrialised countries accounted for 84 per cent of the world's R\&D spending (Keller, 2004, p. 752).

${ }^{7}$ Jones (2002, p. 127).

${ }^{8}$ Appendix 1 presents the closed-form solution of the development of relative technology $B_{t}$.
} 


$$
\begin{aligned}
\delta_{h(t)} & \approx g\left(B^{*}\right)^{\gamma}\left(B^{*}\right)^{-\gamma}\left[1+\gamma\left(\ln B^{*}-\ln B_{t}\right)\right] \\
& =g\left[1+\gamma\left(\ln B^{*}-\ln B_{t}\right)\right] \\
& =g+\gamma g \ln B^{*}-\gamma g \ln B_{t} .
\end{aligned}
$$

As $B_{t}=h_{t} / A_{t}$,

$$
\delta_{B(t)}=\delta_{h(t)}-\delta_{A(t)}=\delta_{h(t)}-g
$$

and, with (6),

$$
\delta_{B(t)}=\frac{d \ln B_{t}}{d t} \approx \gamma g \ln B^{*}-\gamma g \ln B_{t}
$$

Denoting $\ln B_{t}=Z_{t}$, and assuming the equality holds, equation (7) is a simple linear differential equation of the type

$$
\dot{Z}_{t}=\gamma g Z^{*}-\gamma g Z_{t}
$$

with the straightforward solution

$$
Z_{t}=Z_{0} e^{-\gamma g t}+Z^{*}\left(1-e^{-\gamma g t}\right)
$$

Accordingly,

$$
\ln B_{t}=\ln B_{0} e^{-\gamma g t}+\ln B^{*}\left(1-e^{-\gamma g t}\right)
$$

and

$$
\ln B_{t}-\ln B_{0}=\left(1-e^{-\gamma g t}\right)\left(\ln B^{*}-\ln B_{0}\right)
$$

Substituting back for $\ln B_{t}=\ln h_{t}-\ln A_{t}$,

$$
\ln h_{t}-\ln h_{0}-\ln A_{t}+\ln A_{0}=\left(1-e^{-\gamma g t}\right)\left(\ln B^{*}-\ln B_{0}\right)
$$

and

$$
\ln h_{t}-\ln h_{0}=\left(\ln A_{t}-\ln A_{0}\right)+\left(1-e^{-\gamma g t}\right)\left(\ln B^{*}-\ln B_{0}\right)
$$


The world technology frontier is assumed to expand at a constant rate, $g$, according to $A_{t}=A_{0} e^{g t}$ such that $\ln A_{t}=\ln A_{0}+g t$ and

$$
\ln h_{t}-\ln h_{0}=g t+\left(1-e^{-\gamma g t}\right)\left(\ln B^{*}-\ln B_{0}\right)
$$

where $0 \leq \gamma \leq 1$ and $g$, the rate of innovation, is small.

As the time horizon of our empirical assessment will be comparatively short (see section 4.2), we already at this stage approximate $e^{-\gamma g t}$ in (8) by $1-\gamma g t$, such that $1-e^{-\gamma g t}=\gamma g t$. Consequently,

$$
\ln h_{t}-\ln h_{0}=g t+\gamma g t\left(\ln B^{*}-\ln B_{0}\right)
$$

and

$$
\left(\ln h_{t}-\ln h_{0}\right) / t=g+\gamma g \ln B^{*}-\gamma g \ln B_{0} .
$$

From the definition of the steady-state in (5), $\ln B^{*}=\gamma \ln \mu-\gamma \ln g+\gamma \psi u$, such that

$$
\left(\ln h_{t}-\ln h_{0}\right) / t=\left(g-\gamma \ln g+\gamma g \ln A_{0}\right)-\gamma g \ln h_{0}+\gamma \ln \mu+\gamma \psi \mu,
$$

where $\left(\ln h_{t}-\ln h_{0}\right) / t$ is the average yearly rate of change of an observed measure of technology, such as the variety of available capital goods, which depends negatively on initial variety and positively on the steady state, i.e. on human capital parameters.

\section{Measuring available product variety and some stylised facts}

Goods may be available in a country due to production at home or from imports. Variety measures are therefore commonly derived from detailed data on merchandise trade, where export variety is taken to proxy the variety of domestic production. Trade-based count measures of item variety then simply record the number of different items exported, imported or available (i.e., either exported or imported or both), where data detail obviously depends on the level of aggregation of the trade classification used. 
One way to increase data detail is to differentiate items by their country of origin, such that a German car is differentiated from a Japanese car, etc. Using the country of origin of imports enables us to introduce an additional dimension of variety, one which is absent in other data sources. The number of items produced at home (proxied by the number of exported items) plus the number of imported items times their places of origin then corresponds to a count measure, which we term the variety of goods or products available within a country, i.e. available product variety. In this paper, we will deal exclusively with this definition of variety.

Variety measurement may go beyond counting. More sophisticated measures include specialisation indices and especially Feenstra's (1994) exact measure of product variety constructed from a CES function when products enter non-symmetrically. However, the procedure requires the definition of a set of products common to all countries, which is usually achieved by defining a benchmark country. With our definition of variety reflecting also country of origin, this would require defining a benchmark geographic structure of trade, something we regard as overly restrictive. Therefore, in this trade-off between exact theoretical foundation and empirical accessibility we choose to resort to the simpler count measurement of product variety described above.

Thus, we proxy available product variety by measures derived from merchandise export and import data according to the highest aggregation level of the SITC, Rev. 3 (5- and 4-digit basic headings). ${ }^{9}$ Our data set covers exports and imports of 46 countries-reporters, among them transition economies from eastern Europe, the CIS and OECD economies from Europe and North America, between 1992 and 2004 in their trade with the rest of the world and with 55 selected partner countries, which account for the bulk of their trade. The level of aggregation of these data covers 3,114 basic headings referred to as items, while the United Nations Statistics Division's Classification by Broad Economic Categories (BEC) allows for these items to be grouped into the three basic SNA categories, namely 471 capital good items, 1,899 intermediate good items and 704 consumer good items. Consequently, our definition of available product variety as the number of exported items plus the number of imported items times their places of origin defines a maximum count of available

\footnotetext{
${ }^{9}$ For a comprehensive description of our trade-based variety measurement, see Appendix 2.
} 
product variety of all items of 174,384 , since we assume that the country-reporter plus all 55 partner countries could each supply all 3,114 items to a country-reporter. With an average of 40.2 countries reporting per year between 1992 and 2004, computing our product variety measures thus requires the manipulation of some 90 million data points.

In Figure 1 we present available product variety count measures by BEC categories for the year 2000. Countries are ranked in descending order of available product variety for capital goods but sorting countries by each measure of variety reveals more or less the same rough groupings: the highest degrees of variety occur in west European and North American economies, followed by east European EU member countries, then by southeastern Europe, and finally the CIS. There are a few notable exceptions to the general pattern, however, the most striking being Iceland, Cyprus, and Malta among the western economies and Russia among the transition countries. The three very small countries that specialise in producing and exporting a narrow range of goods and services are in the lowest ranks with respect to available variety, while Russia displays degrees of variety similar to that of the high-income economies.

- Figure 1 about here -

The fact that Russia, and also Ukraine, stand out from the other CIS countries in variety terms in part reflects the legacy of the Soviet Union's central planning system, which determined who produced what and did not reflect comparative advantages across the Union. Hence, while many ex-Soviet republics produced too little variety, Russian and Ukrainian enterprises were subsidised to produce too much of it, albeit of low quality. ${ }^{10}$

During our period of observation, product variety increases in western Europe and North America were almost entirely due to the "geographic spread of trade," i.e. to trading with more partners than before, and only marginally to more items being produced or imported at our level of aggregation. ${ }^{11}$ For the reforming east European

\footnotetext{
${ }^{10}$ Russia remains a major supplier of industrial goods to most of its CIS neighbours and to other, mainly developing, economies. In our previous work in UNECE (2004), we report a notable discrepancy between Russia's high rank (and also Ukraine's, to some extent) for variety and its low rank for quality, which to a certain degree reflects a delay in industrial restructuring.

${ }^{11}$ For data on 1992-2001, see Table 6.22 in UNECE (2004, p. 150). On the export side, this particular
} 
and CIS economies, however, both factors played an important role. A rapid liberalisation of their trade led to a geographical diversification that went well beyond the substitution of new western for old eastern trading partners. However, during the 1990s, there were also many more items being produced at home and exported than before, which allow for an important increase in variety available domestically in most east European and CIS economies. This applies especially to capital and intermediate goods, the relative variety of which used to lag behind that of consumer goods in many of these economies prior to reforms. This corresponds to Kehoe and Ruhl's (2002) result that trade liberalisation generally implies that goods traded the least prior to liberalisation account for much higher shares afterwards.

\section{Empirical assessment}

\subsection{Assessing technical change through product variety}

Testing whether trade-based measures of available product variety indeed contain information on technology requires making use of the data within an econometric framework that matches the conditional technological convergence hypothesis (9) as closely as possible. Any such attempt is deeply imbedded in the interdependence between technology, trade, and income. Resolving this interdependence would call for a simultaneous equations approach: variety should depend on trade, trade on income, and income on variety via a technology channel. Modelling this would probably be very demanding, especially when considering the hitherto unclarified nature of the trade-income relationship (cf. Rodríguez, 2006).

Rather, given the BEC categorisation of our variety measures in consumption, intermediates and capital goods, we formulate a short-cut through this web of endogeneity. We argue that consumption variety is a pure trade measure and does not contain any information on technology, i.e., consumer product variety depends on income via trade but does not influence income via a technology channel. 
Accordingly, we define two potential technology-relevant variety measures as (1) the product variety of capital goods relative to the product variety of consumer goods, i.e. $C G V_{j t}=\operatorname{VarCap}_{j t} / \operatorname{VarCon}_{j t}$, and (2) the product variety of intermediate goods relative to the product variety of consumer goods, i.e. $I G V_{j t}=\operatorname{VarInt}_{j t} / \operatorname{VarCon}_{j t}$, where $\operatorname{VarCap}_{j t}, \operatorname{VarInt}_{j t}$ and $\operatorname{VarCon}_{j t}$ are the product variety count measures of country $j$ at time $t$ of available capital, intermediate and consumer goods, respectively, measured as the number of exported items plus the number of imported items times their places of origin. Both measures potentially influence income via a technology channel but do not depend on trade - and thus on income - unless there are asymmetrical effects on capital, intermediate, and consumption variety via trade, for which we will have to control.

\subsection{Data and specification}

\section{Dependant variables}

We will test the conditional technological convergence hypothesis (9) on average yearly growth rates of our two potential technology-relevant variety measures defined above, i.e. on $\left(\log C G V_{j, t+T}-\log C G V_{j t}\right) / T$ and $\left(\log I G V_{j, t+T}-\log I G V_{j t}\right) / T$, with $T$ as the length of the period under consideration.

\section{State variables}

In the framework of conditional technological convergence, initial states are given by $\log C G V_{j t}$ or $\log I G V_{j t}$, respectively.

On the right hand side of equation (9), $u$ refers to the length of schooling, $\psi$ to the returns to schooling, and $\mu$ is an efficiency parameter of learning, all of which are presumably interdependent: the individual choice of length of schooling responds to the returns to schooling, which, in turn, depend on the institutional environment that mirrors the efficiency of learning in a society. Here, however, we abstract from these interdependencies and retreat to the usual assumptions prevailing in the empirical 
literature on skill acquisition and learning and assume especially that $\psi$ is constant and equal to 0.1 , such that one additional year of schooling is rewarded by a 10 per cent increase in income.

The efficiency parameter of learning, $\mu$, might perhaps best be understood as measuring a wide array of additional, institution related steady state parameters other than human capital to influence technology transfer and adoption. However, rather than introducing additional differences among countries as outright explanatory variables, we will make use of them in our sensitivity analysis further below.

This leaves us with one steady state variable, i.e. the length of schooling measured in average years per person. Rather than using schooling data for the whole population, we define as our main steady state variable $u 25 f$, i.e. the average years of school of the female population aged 25 and over. Why female? Provided that females have so far been disadvantaged in education in most countries, female schooling measures are in fact preferable to total population measures, as their change signals change in both mean and variance of total population educational attainment, both of which are conducive to increases in human capital levels. We use data from the updated BarroLee set (Barro and Lee, 2000) with the caveat that for our purposes this data set, while representing the best available, has two shortcomings: first, we know that individuals also acquire skills outside of formal education, and experience is about as important as formal education. Second, the Barro-Lee data set contains only limited information on transition economies (for more detail, see Table A3 in the appendix).

\section{Control and environment variables}

As indicated above, both $\left(\log C G V_{j, t+T}-\log C G V_{j t}\right) / T$ and $\left(\log I G V_{j, t+T}-\log I G V_{j t}\right) / T$ are subject to potential asymmetrical effects via trade, for which we have to control. We do so by including inv_con ${ }_{j, t+T}-i n v_{-} c o n_{j t}$, i.e. the period change in the investment-consumption ratio, to control for specific demand effects on different BEC categories.

As found in Hummels and Klenow (2005), country size matters for variety. Especially, variety in capital goods involves economies of scale and may thus imply a 
threshold size, below which very small countries' available product varieties do not converge with the same speed as larger countries' do according to (9). We capture this size effect on specialisation and variety patterns with a variable, which interacts a microstate dummy for populations less than 1 million, Micro1, with the initial state of variety. In the sensitivity test further below, we will test alternative microstate dummies.

Finally, we need an additional environment variable to take account of special, transition-related effects on variety. ${ }^{12}$ In a first specification - in analogy to the microstate dummy - we simply interact a transition country dummy, Trans, with the initial state of variety.

Table A3 in the appendix summarises the description of all variables used in the regression analysis.

\section{Specification}

Our main steady state variable, i.e., length of schooling, is available only at five-year intervals $(1995,2000)$. This fact alone makes clear that we cannot exploit the full 1992-204 panel of variety data we have.

In addition, in choosing an estimation approach we rely on the experience with estimating conditional per capita income convergence. There has been a long-running debate in per capita income growth empirics on how to exploit the variation available in panel data. If per capita income growth depends on the initial level of technology, omitting this variable causes heterogeneity bias: in the absence of measurement error using only within-country variation dominates any estimators using also between country variation. Without omitted variable bias but in the presence of measurement error, and when explanatory variables are more time persistent than measurement error, the opposite is true. ${ }^{13}$

\footnotetext{
${ }^{12}$ See Frensch ( 2004) for a theoretical justification that improvements in public governance, which are connected to a successful political transformation, facilitate variety gains during transition.

${ }^{13}$ Provided all our countries are "small" relative to the technology frontier, our approach should not suffer from country heterogeneity bias. To make sure, we will in our sensitivity analysis construct a
} 
Hauk and Wacziarg (2004) perform a Monte Carlo study to assess the effects of both sources of bias on various estimators used in per capita income growth regressions and find that within estimators greatly overstate the speed of convergence and bias steady state variable estimates towards zero. Estimators that use at least some between variation tend to overestimate steady state variable influence and are probably closer to the true speed of convergence. Especially, the SUR estimator used in Barro and Sala-i-Martin (2004) performs best in terms of estimating speed of convergence. The between estimator (OLS applied to a single cross-section averaged over time) performs best in terms of overall bias.

With potential mismeasurement in our trade data measuring available product variety, the above argument points towards employing a traditional between estimator in our context of conditional technological convergence estimation. Our main limitation here is data availability: after data cleaning (see Appendix 2), the maximum number of observations over a period somewhat longer than five years is around 40 . We can increase this by about two thirds by using data from two five-year periods (1993-98 and 1999-2004).

Accordingly, we compromise between data availability and measurement bias by using data from two five-year periods and estimating this small panel with 3SLS (as in Barro and Sala-i-Martin, 2004, chapter 12, in the context of per capita income convergence), i.e., the two-stage least squares version of the SUR method, an estimation technique less prone to measurement bias than other panel estimators, and appropriate when there may be both heteroskedasticity and contemporaneous correlation in the residuals. $^{14}$

smaller sample excluding those countries where this assumptions seems in doubt due to their prominence in innovation activity.

${ }^{14}$ In the per capita income convergence literature close to our approach measurement bias of initial states is also dealt with by using lagged initial state variables as instruments, usually lagged for the length of one period, i.e. five years in our context. Our data, however, start only with 1992 and thus allow only for a one year lag. Using this lagged state variable as instrument results in our system being just identified, so we cannot properly test for the validity of these instruments, e.g. with a Sargan test. 


\subsection{Estimation and discussion of the results}

Based on our hypothesis (9), we thus have as the initial state variable the product variety of capital goods relative to the product variety of consumer goods, i.e. $\log$ $C G V_{j t}=\log \left(\operatorname{VarCap}_{j t} / \operatorname{VarCon}_{j t}\right)$, or the product variety of intermediate goods relative to the product variety of consumer goods, i.e. $\log I G V_{j t}=\log \left(\operatorname{VarInt}_{j t} / \operatorname{VarCon}_{j t}\right)$, three variables controlling, respectively, for specific demand effects on different BEC categories $\left(i n v \_c o n_{j, t+T}-i n v_{-}\right.$con $\left.n_{j t}\right)$, for size effects $\left(\right.$ Micro $1 \times \log C G V_{j t}$ or Micro $1 \times \log$ $\left.I G V_{j t}\right)$, and for transition $\left(\right.$ Trans $\times \log C G V_{j t}$ or $\left.\operatorname{Trans}^{\times} \times \log I G V_{j t}\right)$, and one steady-state variable, $u 25 f_{j, t T}$, for the period $t T$ between $t$ and $t+T$. We accordingly estimate

$$
\begin{aligned}
\left(\log C G V_{j, t+T}-\log C G V_{j t}\right) / T= & \alpha_{0}+\alpha_{1} \log C G V_{j t}+\alpha_{2} u 25 f_{j, t T}+\alpha_{3}\left(i n v_{-} c o n_{j, t+T}-i n v_{-} c o n_{j t}\right) \\
& +\alpha_{4} \text { Micro } 1 \times \log C G V_{j t}+\alpha_{5} \text { Trans } \times \log C G V_{j t}+\varepsilon_{j t},
\end{aligned}
$$

with available capital goods variety data, and

$$
\begin{aligned}
\left(\log I G V_{j, t+T}-\log I G V_{j t}\right) / T= & \beta_{0}+\beta_{1} \log I G V_{j t}+\beta_{2} u 25 f_{j, t T}+\beta_{3}\left(i n v_{-} c o n_{j, t+T}-i n v_{-} c o n_{j t}\right) \\
& +\beta_{4} \text { Micro } 1 \times \log I G V_{j t}+\beta_{5} \text { Trans } \times \log I G V_{j t}+\eta_{j t},
\end{aligned}
$$

with available intermediate goods variety data. A priori expectations from (9) and the discussion in the previous section are that $\alpha_{1}, \alpha_{5}, \beta_{1}, \beta_{5}<0$

and $\alpha_{2}, \alpha_{3}, \alpha_{4}, \beta_{2}, \beta_{3}, \beta_{4}>0$. Instruments are the one period-lagged initial state variables. (10) is tested over an unbalanced panel of countries over two intervals of equal length $T=5,1993-98$ and 1999-2004, i.e. as a system of two equations.

Estimation is by three-state-least squares allowing the error terms to have different variances in the two intervals and to be correlated across intervals.

Estimation result are given in Table 1. Coefficients of control variables have the expected signs and are all significant in the CGV estimation (capital goods, Table 1, 
column 1), not so in the IGV estimation (intermediate goods, Table 1, column 2). Especially, transition does not have a significant effect on IGV growth and very small countries appear to have a higher instead of the expected lower rate of IGV convergence.

- Table 1 about here -

Comparing CGV and IGV estimations also reveals important differences with respect to the significance of schooling and the estimated speed of convergence. Average length of schooling of the female population over 25 years of age exerts a significant effect on the growth of available product variety of capital but not so on the growth of available product variety of intermediate goods. This is perfectly in line with the conditional technological convergence hypothesis: the division of labour can be expected to be embedded in the variety of available capital goods, much more so than in the variety of intermediate goods, as a direct measure of the state of technology. As is to be expected from the hypothesis (9), the effect of schooling on variety growth is rather small: increasing length of schooling of the female population over 25 years of age by one year increases the yearly average growth rate of the variety of available capital goods by about 0.0012 , i.e. when expressing growth rates in percentages, this amounts to slightly less than one eighth of a percentage point. Equivalently, ceteris paribus it takes an increase of about four years in the average length of schooling of the female population over 25 years of age to bring about a half a percentage point increase in the yearly average growth rate of the variety of available capital goods.

For their full sample of countries, Barro and Sala-i-Martin (2004, Table 12.3, p. 522), report a conditional convergence speed of real per capita GDP of $2.5 \%$. If conditional technological convergence were considerably higher than this, technological differences would wear out over time in explaining per capita income differences, which is counterfactual, as empirically productivity differences explain most of the variation in per capita incomes across countries, and the way factors are transformed into output, i.e. production technology is the key to determining productivity. Indicating an estimated speed of conditional technological convergence of $2.7 \%$, CGV results in Table 1, column 1, match Barro and Sala-i-Martin's well. The speed of convergence from the intermediate goods variety regressions in column 2 of almost $4 \%$ seems too high to be consistent with conditional technological convergence in the 
context outlined above.

The first evidence thus seems to point towards the direction that trade-based count measures of the product variety of available capital goods indeed behave "as if" they represent technology in the sense of the conditional technological convergence hypothesis (9), while measures of the variety of intermediate products do not.

\section{Policy reforms in transition}

So far, we have not specified how exactly transition exerts an influence on the speed of technological convergence. Within our approach, studying this in more detail means searching for a policy reform area that influences trade and the technology channel of trade significantly differently. The variables most in use for such a purpose are the EBRD transition indicators, measured on a scale between levels 1 and $4+(=$ 4.33). I.e., these variables are ordered qualitative rather than cardinal measures and should perhaps best not be used directly in linear regression analysis. Rather, we construct dummy variables from these EBRD indicators in the general form of ReformMeasure_Level $j_{j, t}$, indicating whether or not a country has within a certain policy field made the step towards a certain level on the EBRD scale within a given period. We define six such measures (Table A3) and interact them with the speed of convergence, where we acknowledge that reform progress in different fields has been of different speed, i.e. we consider levels on the EBRD scale, which create sufficient variability in the data. ${ }^{15}$

Policy reforms may not be exogenous because of potential reverse causality from technology via per capita income growth on reforms, or because of common effects of omitted variables on both technical change and reforms (e.g., the often quoted “distance to Brussels"). However, Godoy and Stiglitz (2006) show in a simultaneous equations approach that there is no significant endogeneity problem in the per capita growth and policy reforms context. As income growth appears to be the only potential channel between technology and reforms, we thus take policy reforms to be

\footnotetext{
${ }^{15}$ E.g., in the period under consideration, no transition country has reached "level 4" on the EBRD scale in terms of banking reform. Attempts to study the corresponding impact on variety change thus make little sense.
} 
exogenous for our purposes.

From Aghion, Howitt and Mayer-Foulkes (2005) one might expect that banking reform has a positive impact on technical change over and above that on trade, while there is no clear cut a priori expectation on the direction of influence of other policy reforms. We therefore substitute our preliminary transition control variables Trans $\times \log C G V_{j t}$ and Trans $\times \log I G V_{j t}$, respectively with $\left(B a n k \_2_{j, t T} \times \log C G V_{j t}\right)$ in our specification (10a), and with (Bank_ $\left.2_{j, t} \times \log I G V_{j t}\right)$ in (10b), where Bank_2 $2_{j, t T}$ indicates whether or not a country has made the step towards level 2 in the EBRD scale in the area of banking reform and interest rate liberalisation within a given period.

Results in Table 2 partly confirm our expectations, as banking reforms exert a significant - and positive - effect on the speed of CGV convergence (column 3 in Table 2).

- Table 2 about here -

Substituting the transition dummy in the CGV estimation by a specific banking reform variable slightly increases the point estimate of speed of convergence, while leaving the point estimate of the schooling variable unchanged. While the microstate variable point estimate increases slightly, the point estimate of the investmentconsumption ratio influence is substantially reduced. The significance of estimated coefficients and the overall fit of the CGV estimation is substantially improved (column 3, Table 2 versus column 1, Table 1).

Surprisingly, however, the impact of banking reforms during transition is negative on the speed of IGV convergence (column 5 in Table 2), while at the same time the relatively high speed of convergence estimate is only very slightly reduced and the effect of schooling remains insignificant.

To test for potential misspecification, we applied a systems version of Ramsey's Reset-test in form of a Wald-test on polynomials of second, third and fourth order, respectively, of the fitted values from column 3 and 5 regressions in Table 2. In none of these tests could we reject the null of zero coefficients of these polynomials for the CGV model. However, we had to reject the hypothesis of a zero coefficient for the 
third order (at 1 percent level of significance) and also for the fourth order fitted values polynomial (at 10 percent level of significance) for the IGV model.

Summing up this evidence, we take Table 2 results as substantiating our first impression that trade-based count measures of the product variety of available capital goods indeed behave as if they represent technology, while measures of the product variety of available intermediate goods do not. But how robust are these results?

\section{Sensitivity}

\section{$\underline{\text { Sample composition }}$}

In deriving our conditional technological convergence hypothesis we assumed that countries are small in the sense of taking the expansion of the frontier technology as given. We therefore construct a "small country" sample excluding countries where this assumption seems in doubt due to their prominence in innovation activity (see $\mathrm{fn}$. 6), thus reducing potential country heterogeneity bias if the small country assumption were wrong. Comparing columns (4) and (6) in Table 2 to columns (3) and (5), respectively, shows that point estimates and levels of significance of coefficients are quite robust to sample composition.

\section{$\underline{\text { Alternative microstate definitions }}$}

We argue that there may exist a threshold size, below which very small countries do not exhibit product variety - and thus conditional technological - convergence with the same speed as larger countries do and capture this effect with a control variable, which interacts initial state variables with a microstate dummy for populations of less than 1 million in our preferred benchmark specification in column 3, Table 2 . As this is a rather $a d$ hoc definition, we test the robustness of our results against two alternative microstate definitions (see Table A3 in the appendix): Micro2 for a labour force of less than 1 million, and Micro3 for a labour force of less than 2 million, respectively.

CGV results are presented in Table 3 and indicate that "wider" definitions of a 
microstate variable in columns 7 and 8 somewhat lessen the estimated speed of convergence without substantially altering the results otherwise. Hence we conclude that our result are quite robust to the definition of microstates (IGV results are available upon request).

- Table 3 about here -

\section{Alternative schooling variables}

Except for our preferred schooling measure $u 25 f$, we test the robustness of our benchmark results in column 3 of Table 2 to alternative measures of schooling, where $u 15 f, u 25$, and $u 15$, indicate average years of school of the female (for $f$ ) or total population aged 15 (25) and over. As Table 4 indicates, all alternative schooling measures are significant in CGV estimations, without substantially altering point estimates and significance levels of other coefficients. As none of our alternative schooling measures turns out significant in our IGV regressions (available upon request), we conclude that our result are robust to the measurement of educational attainment.

- Table 4 about here -

\section{Additional policy reforms in transition}

We have already indicated that - except for banking reform - we constructed five additional policy reform measures in the general form of ReformMeasure_Level ${ }_{j, t}$, indicating whether or not a country has within a certain policy field made the step towards a certain level in the EBRD scale within a given period (for details see Table A3). However, none of these turned out significant in either CGV or IGV benchmark estimations (columns 3 and 5, Table 2). Results are available upon request.

\section{$\underline{\text { Additional steady state regressors }}$}

A strong case can be made that the Reset test on our benchmark specification above can test only for functional form misspecification, rather than for omitted variables. 
We therefore also test the influence of additional variables that could potentially act as institutionally-backed steady state regressors influencing technical progress in our hypothesis (9), namely the mid-period levels of population density and the share of urban population, and the mid-period logs of the sum of residents' and non-residents' patent applications and the sum of residents' and non-residents' patent applications per employee, respectively (all drawn from the World Bank's World Development Indicators, WDI 2006). None of these additional regressors turned out significant in either CGV or IGV benchmark estimations (columns 3 and 5, Table 2). Again, results are available upon request.

\section{Conclusions}

The results of this paper constitute evidence on the issue of direct measurement of technology by trade-based measures of product variety. Trade-based count measures of the variety of available capital goods indeed behave "as if" they were representing technology, while measures of the variety of available intermediate products do not, both contingent on our assumption that the variety of consumer goods does not carry information on technology. Based on available capital goods variety estimations, there is conditional technological convergence among a set of mostly OECD and transition countries, where the speed of convergence corresponds to that of real per capita income arrived at with comparable estimation techniques. Extending the analysis to allow for various transitional reforms to influence technological convergence shows that only banking reforms exert a significant - and positive - effect on the speed of technological convergence.

Against the background of the recent, rather indiscriminate use of various trade-based measures of the variety of production as if implicitly representing states of technology, our results imply that caution is needed when constructing such measures: measures that include information on the variety of consumption and/or intermediate goods and/or only on export variety rather than available variety seem unwarranted.

The implications for further research are manifold. Both theoretically as well as empirically, an integration of trade-based variety and quality measures to better proxy 
the extent and the quality of the division of labour as a measure of technology is called for. Finally, if available intermediate goods variety is not a technological variable, what then is it?

\section{References}

Addison, Douglas M., Productivity growth and product variety: gains from imitation and education. World Bank Policy Research Paper 3023, Washington, April 2003.

Aghion, Philippe, Peter Howitt, and David Mayer-Foulkes, The effect of financial development on convergence: theory and evidence. Quarterly Journal of Economics 120, 1, February 2005, pp. 173-222.

Barro Robert J., and Jong-Wha Lee, International data on educational attainment. Updates and implications. NBER Working Paper 7911, September 2000.

Barro, Robert J., and Xavier Sala-i-Martin, Economic Growth. $2^{\text {nd }}$ edition, MIT Press, Cambridge MA and London, 2004.

Basu, Susanto, and David Weil, Appropriate technology and growth. Quarterly Journal of Economics 113, 4, 1998, pp. 1025-54.

Comin, Diego, and Bart Hobijn, Cross-country technology adoption: making the theories face the facts. Journal of Monetary Economics 51, 2004, pp. 39-83.

Evenett Stephen, and Anthony Venables, Export growth in developing countries: market entry and bilateral trade flows. Mimeo, World Trade Institute, Bern, July 2002.

Feenstra, Robert C., New product varieties and the measurement of international prices. American Economic Review 84, 1, March 1994, pp. 157-77.

Feenstra, Robert C., D. Madani, T. Yang and C. Liang, Testing endogenous growth in South Korea and Taiwan. Journal of Development Economics 60, 2, 1999, pp. 317-41.

Frensch, Richard, Public governance as the source of quality and variety gains from transition. Journal of Comparative Economics 32, 3, September 2004, 388-408.

Funke, Michael, and Ralf Ruhwedel, Product variety and economic growth: empirical evidence for the OECD countries. IMF Staff Papers 48, 2, December 2001, pp. 225-42.

Funke, Michael, and Ralf Ruhwedel, Export variety and economic growth in East European transition economies. Economics of Transition 13, 1, 2005, pp. 25-50.

Gerschenkron, Alexander, Economic backwardness in historical perspective, in: Hoselitz, Bert F. (ed.), The Progress of Underdeveloped Areas. University of Chicago Press, Chicago, 1952.

Godoy, Sergio, and Joseph Stiglitz, Growth initial conditions, law and speed of privatization in transition countries: 11 years later. NBER Working Paper 11992, Cambridge, MA, January 2006.

Hauk, William R., and Romain Wacziarg, A Monte Carlo study of growth regressions. NBER Technical Working Paper 296, Cambridge, MA, January 2004.

Hummels, David, and Peter J. Klenow, The variety and quality of a nation's exports. 
American Economic Review 95, 3, June 2005, pp. 704-23.

Jones, Charles I., Introduction to Economic Growth, $2^{\text {nd }}$ edition. W.W. Norton, New York and London, 2002.

Jones, Charles I., A note on the closed-form solution of the Solow model. Mimeo, available online at http://emlab.berkeley.edu/users/chad/papers.html\#closed form

Kehoe, T., and K. Ruhl, How important is the new goods margin in international trade?" Mimeo, University of Minnesota, October 2002.

Klenow, Peter J., and Andrés Rodríguez-Clare, Quantifying variety gains from trade liberalization. Mimeo, Graduate School of Business, University of Chicago, September 1997.

Keller, Wolfgang, Absorptive capacity: on the creation and acquisition of technology in development. Journal of Development Economics 49, 1, April 1996, pp. 199-227.

Keller, Wolfgang, International technology diffusion. Journal of Economic Literature 42, 3, 2004, pp. 752-82.

Nelson, Richard, and Edmunds Phelps, Investment in humans, technological diffusion and economic growth. American Economic Review 56, 2, 1966, pp. 69-75.

Rodríguez, Francisco, Openness and growth: what have we learned? Background note for the United Nations' 2006 World Economic and Social Survey, Wesleyan University, 2006.

Romer, Paul, Endogenous technological change. Journal of Political Economy 98, 5, October 1990, pp. S71-S102.

UNECE, The benefits from product differentiation in modern economies. Economic Survey of Europe 2004, 1, United Nations, Geneva, 2004, pp. 145-62.

United Nations Statistics Division, Methods and classifications: Classification by Broad Economic Categories, defined in terms of SITC, Rev.3, (BEC Rev.3). Available online at: http://unstats.un.org/unsd/cr/family2.asp? $\mathrm{Cl}=10$ 


\section{Appendix 1: A closed-form solution for relative technology $B_{t}$}

We start out with technical change as described in (4). Define the technology of a country relative to the frontier as $B_{t}=h_{t} / A_{t}$, and the respective rate of growth as $\delta_{B(t)}=\delta_{A(t)}-\delta_{h(t)}$. Assume that the technological frontier grows autonomously according to $A_{t}=A_{0} e^{g t}$, and that $g$ is given to any single country in the world such that $\delta_{B(t)}=\delta_{A(t)}-g$. Then, (4) can be rewritten as

$$
\delta_{B}+g=\mu e^{\psi u} B_{t}^{-\gamma}
$$

or equivalently as

$$
\frac{\dot{B}_{t}}{B_{t}}=\mu e^{\psi \imath} B_{t}^{-\gamma}-g
$$

and

$$
\dot{B}_{t}=\mu e^{\psi u} B_{t}^{1-\gamma}-g B_{t}
$$

(A1) is a Bernoulli-equation, which can be transformed into an ordinary linear differential equation by setting $Z_{t}=B_{t}^{\gamma}$, and accordingly $\dot{Z}_{t}=\gamma B_{t}^{\gamma-1} \dot{B}_{t}$. Then, (A1) becomes

$$
\frac{\dot{Z}_{t}}{\gamma}=\mu e^{\psi u}-g z_{t}
$$

and thus

$$
\dot{Z}_{t}=\gamma \mu e^{\psi u}-\gamma g z_{t}
$$

(A2) has the straightforward solution

$$
Z_{t}=Z_{0} e^{-\gamma g t}+\frac{\mu}{g} e^{\psi u}\left(1-e^{-\gamma g t}\right)
$$

such that

$$
B_{t}^{\gamma}=B_{0}^{\gamma} e^{-\gamma g t}+\frac{\mu}{g} e^{\psi \mu u}\left(1-e^{-\gamma g t}\right)=B_{0}^{\gamma} e^{-\gamma g t}+\left(B^{*}\right)^{\gamma}\left(1-e^{-\gamma g t}\right)
$$

The resemblance to the derivation of the closed-form solution for per capita income in the Solow model (Jones, mimeo) is evident and noteworthy. 


\section{Appendix 2: Trade-based measurement of variety}

For this paper, the data for the trade-based variety measures were extracted from the United Nations COMTRADE database in November 2005. The cut-off value for the selection of items is $\$ 501$ (which is rounded to $\$ 1,000$ ).

\section{Commodity classifications}

The Standard International Trade Classification, Revision 3 (SITC, Rev.3) was used at all aggregation levels (1-, 2- and 3-digit levels for checking totals, 4- and 5-digit levels for counting item variety).

There are 3,121 basic headings in the SITC, Rev.3, 2,824 at the 5-digit level and 297 at 4-digits, that are not disaggregated any further. The 3-digit group 334 (petroleum products), which is divided into eight final headings in SITC, Rev.3, is in fact not subdivided by many reporting countries, so in the data set used in this chapter it is also treated as a single heading. Thus, there are 3,114 basic headings, which are referred to as items.

The United Nations Statistics Division's Classification by Broad Economic Categories (BEC) allows for commodities defined in terms of the SITC, Rev.3 to be grouped into 19 basic categories covering primary and processed foods and beverages, industrial supplies, fuels and lubricants, capital goods and transport equipment, and consumer goods according to their durability. The BEC also provides for the rearrangement of these 19 categories (on the basis of commodities' main end-use) to approximate the three basic System of National Accounts (SNA) categories, namely, capital goods, intermediate goods and consumer goods.

Capital goods comprise 471 headings at the 4- and 5-digit levels of the SITC, Rev.3 and include: machinery such as electric generators and computers; industrial transport equipment such as finished ships, road vehicles, aircraft, railway and tramway rolling stock; and other manufactured goods such as medical furniture, which are used by industry, government and non-profit private institutions.

Intermediate goods consist of 1,899 SITC, Rev.3 headings and include: primary and processed food and beverages designated mainly for industry; primary and processed industrial supplies (raw materials), parts and accessories of capital goods; and transport equipment. By definition it should also include primary and processed fuels and lubricants (other than motor spirit), but in this data set "fuels and lubricants", which include 32 4- and 5- 
digit headings of the SITC, Rev.3, are excluded.

Consumer goods cover 704 headings at 4- and 5-digits of the SITC and include primary and processed foods and beverages designated mainly for household consumption, non-industrial transport equipment, such as motorcycles and bicycles, and other consumer goods.

Because it falls into two categories, "motor vehicles for the transport of passengers", SITC, Rev.3, Heading 7812, is not included in either capital or consumer goods. Similar reasoning holds for motor spirits.

BEC 7, "goods not elsewhere classified", comprises 14 basic headings of the SITC, namely, military equipment, including arms and ammunitions, special transactions, postal packages, etc. and are excluded from all three categories.

\section{Country and period coverage}

Reporting countries' data were extracted for 46 UNECE countries, i.e. most of Europe, Central Asia and North America. Belgium and Luxemburg are counted as one country throughout as reported until 1998; for Bosnia and Herzegovina, Tajikistan and Uzbekistan no detailed data available from COMTRADE.

Partner countries comprise the rest of the world (for both total exports and imports and thus for the item variety count), and 55 individual countries (50 UNECE members plus 6 Asian countries: China, Hong Kong, Japan, South Korea, Taiwan and Thailand) for imports and thus for the product variety count. These partner countries generally account for 80-95 per cent of reported imports. However, Canada and the United States trade extensively with south American countries that are not included among the 55 partners, and for this reason the trade partners in this data set cover a somewhat lower share of these countries' total imports.

The data cover 1992-2004 but not all countries report in each year (average: 40.15 countries per year).

\section{Data cleaning}

The most important source of measurement bias in our variety data is potential fluctuation in data coverage on the fairly disaggregate level of SITC we are using, i.e. fluctuations in the 
ratio of reported exports (or imports) of all the individual items and total exports (or imports). Even by eyeballing the data (Table A2), Turkmen, Kazakh and Kyrgyz data disqualify in this respect right away. If we were to normalise the distributions of these coverage fluctuations for the rest of the data over our five-year periods of interest, we would have to forego about ten per cent of the data. Rather than doing this, we dismiss the most obvious remaining outliers, which are the coverage fluctuations in the Croatian data between 1993-98. Consistency checks with the remaining data reveal that all Polish product variety measures double between 2003 and 2004, unaccounted for by any comparable coverage fluctuation but probably due to changes in the methodology since the EU accession. As the emerging distrust comes on top of an often substantial mismatch between Polish customs and balance of payments foreign trade data during the 1990s, we also dismiss Polish data. Given the above procedure, checking for normality of residuals in our estimations is a clear must. 


\section{Appendix 3: Tables and Figures}

Figure 1: Available product variety by Broad Economic Categories in western Europe, North America and the CIS, 2000

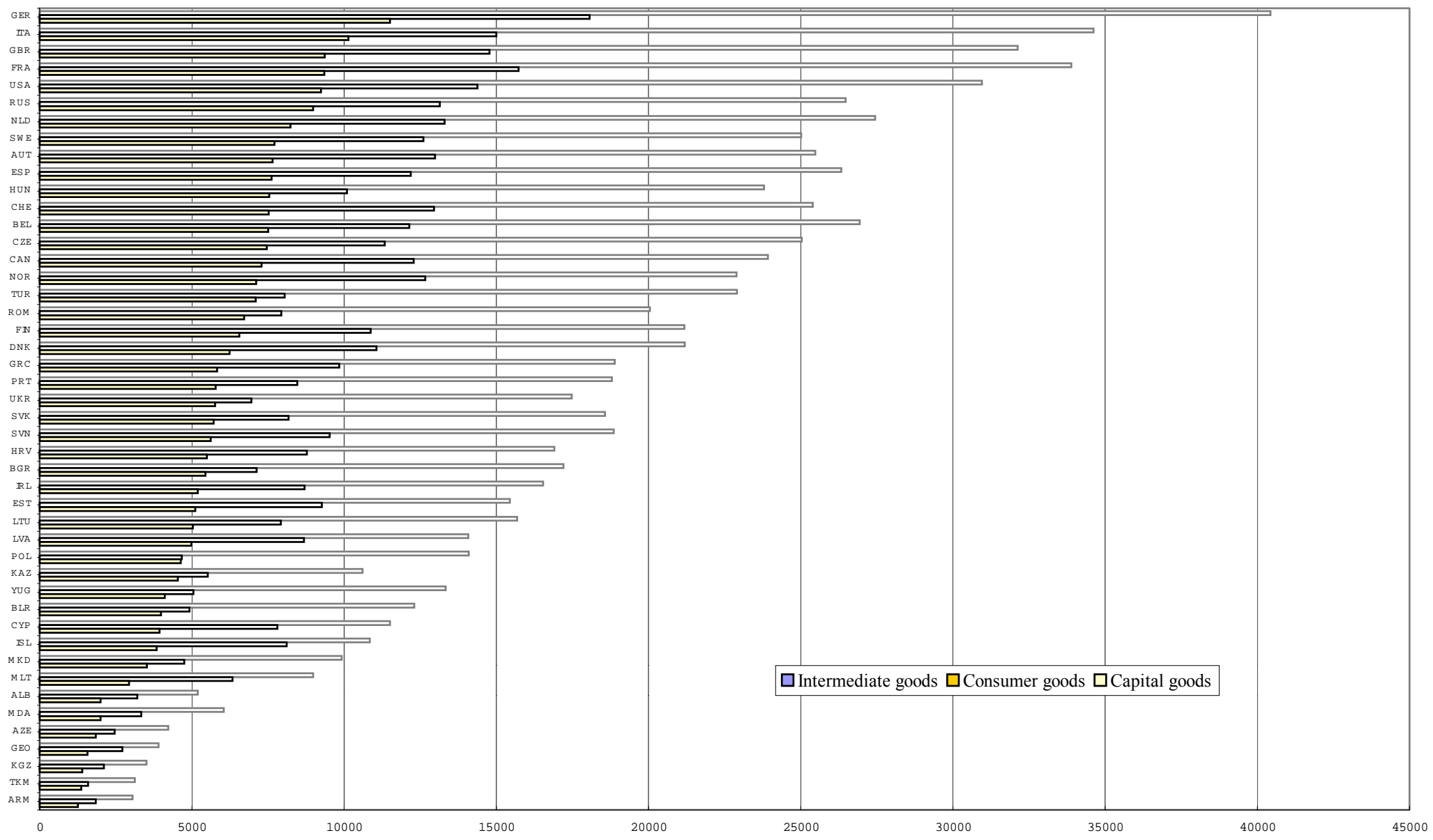

Sources: United Nations COMTRADE database and own calculations.

Notes: The maximum attainable product variety counts are 39,424 for consumer goods, 26,376 for capital goods, and 106,344 for intermediate goods. 


\section{Table 1: Product variety growth regressions (3SLS)}

Dependent variables: Average yearly growth rates of product variety of available capital goods and of available intermediate goods, relative to available consumer goods variety, respectively, $\left(\log C G V_{j, t+T}-\log C G V_{j t}\right) / T$ and $\left(\log I G V_{j, t+T}-\log I G V_{j t}\right) / T$

(1)

Capital goods
(2)

Intermediate goods

\begin{tabular}{|c|c|c|}
\hline Explanatory variables: & & \\
\hline $\begin{array}{l}\text { Initial variety relative to consumer } \\
\text { goods, } \log C G V_{j t}\end{array}$ & $\begin{array}{l}-0.027^{* *} \\
(-2.55)\end{array}$ & \\
\hline or $\quad \log I G V_{j t}$ & & $\begin{array}{c}-0.038^{* * *} \\
(-3.44)\end{array}$ \\
\hline $\begin{array}{l}\text { Average years of schooling, } \\
\qquad u 25 f_{j, t T}\end{array}$ & $\begin{array}{r}0.0012^{*} \\
(1.68)\end{array}$ & $\begin{array}{c}0.0002 \\
(0.32)\end{array}$ \\
\hline $\begin{array}{l}\text { Microstate, } \\
\text { Micro } 1 \times \log C G V_{j t}\end{array}$ & $\begin{array}{l}0.018^{* *} \\
(2.44)\end{array}$ & \\
\hline or $\quad$ Micro $1 \times \log I G V_{j t}$ & & $\begin{array}{c}-0.053^{* * *} \\
(-4.05)\end{array}$ \\
\hline $\begin{array}{l}\text { Investment-consumption ratio change, } \\
\quad i n v_{-} \text {con }_{j, t+T}-i n v_{-} \operatorname{con}_{j t}\end{array}$ & $\begin{array}{c}0.087^{* * *} \\
(4.65)\end{array}$ & $\begin{array}{l}0.050^{* *} \\
(2.35)\end{array}$ \\
\hline $\begin{array}{l}\text { Transition, } \\
\quad \text { Trans } \times \log C G V_{j t}\end{array}$ & $\begin{array}{l}-0.014^{* *} \\
(-2.03)\end{array}$ & \\
\hline or $\quad \operatorname{Trans} \times \log I G V_{j t}$ & & $\begin{array}{l}0.001 \\
(0.32)\end{array}$ \\
\hline Observations (1993-98, 1999-2004) & $64(25,39)$ & $64(25,39)$ \\
\hline Correlation between subperiod residuals & 0.03 & 0.18 \\
\hline Adj. $R$-squared, (1993-98, 1999-2004) & $0.43,0.41$ & $0.37,0.37$ \\
\hline
\end{tabular}

Notes: $t$-statistics in parentheses. ${ }^{*}(* *, * *)$ : significance at $10,(5,1)$ per cent. Instruments: one year lagged initial relative product varieties. Interval dummies not reported. We cannot reject non-normality of second subperiod residuals in (2) on a Jarque-Bera test at 5 per cent level; qualitative results in (2) are robust to removal of an outlier (YUG) normalising residuals, except for a substantial decline in the estimated speed of convergence. 


\section{Table 2: Product variety growth regressions with banking reform in transition}

(3SLS)

Dependent variables: Average yearly growth rates of product variety of available capital goods and of available intermediate goods, relative to available consumer goods variety, respectively, $\left(\log C G V_{j, t+T}-\log C G V_{j t}\right) / T$ and $\left(\log I G V_{j, t+T}-\log I G V_{j t}\right) / T$

\begin{tabular}{|c|c|c|c|c|}
\hline \multirow{3}{*}{ Explanatory variables: } & \multirow{2}{*}{\multicolumn{2}{|c|}{$\begin{array}{l}\text { (3) } \\
\text { Capital goods }\end{array}$}} & & (6) \\
\hline & & & \multicolumn{2}{|c|}{ Intermediate goods } \\
\hline & Full sample & $\begin{array}{l}\text { Small country } \\
\text { sample }\end{array}$ & Full sample & $\begin{array}{l}\text { Small country } \\
\text { sample }\end{array}$ \\
\hline $\begin{array}{l}\text { Initial variety relative to consumer } \\
\text { goods, } \log C G V_{j t}\end{array}$ & $\begin{array}{c}-0.028^{* * *} \\
(-3.24)\end{array}$ & $\begin{array}{l}-0.024^{* *} \\
(-2.58)\end{array}$ & & \\
\hline or $\quad \log I G V_{j t}$ & & & $\begin{array}{c}-0.037^{* * *} \\
(-4.09)\end{array}$ & $\begin{array}{c}-0.040^{* * *} \\
(-3.96)\end{array}$ \\
\hline $\begin{array}{l}\text { Average years of schooling, } \\
\qquad u 25 f_{j, t T}\end{array}$ & $\begin{array}{l}0.0012^{* *} \\
(2.07)\end{array}$ & $\begin{array}{l}0.0016^{* *} \\
(2.31)\end{array}$ & $\begin{array}{c}0.0003 \\
(0.49)\end{array}$ & $\begin{array}{c}0.00003 \\
(0.04)\end{array}$ \\
\hline $\begin{array}{l}\text { Microstate, } \\
\qquad \text { Micro } 1 \times \log C G V_{j t}\end{array}$ & $\begin{array}{c}0.020^{* * *} \\
(3.15)\end{array}$ & $\begin{array}{l}0.018^{* *} \\
(2.66)\end{array}$ & & \\
\hline or $\quad$ Micro $1 \times \log I G V_{j t}$ & & & $\begin{array}{l}-0.054^{* * *} \\
(-5.19)\end{array}$ & $\begin{array}{c}-0.053^{* * *} \\
(-4.76)\end{array}$ \\
\hline $\begin{array}{l}\text { Investment-consumption ratio change, } \\
\quad \text { inv_con }{ }_{j, t+T}-i n v_{-} \text {con }_{j t}\end{array}$ & $\begin{array}{l}0.071^{* * *} \\
(4.57)\end{array}$ & $\begin{array}{c}0.069^{* * *} \\
(4.21)\end{array}$ & $\begin{array}{l}0.034^{*} \\
(1.92)\end{array}$ & $\begin{array}{l}0.037^{*} \\
(1.91)\end{array}$ \\
\hline $\begin{array}{l}\text { Banking reform, } \\
\qquad \text { Bank } 2_{j, t T} \times \log C G V_{j t}\end{array}$ & $\begin{array}{c}-0.065^{* * *} \\
(-5.59)\end{array}$ & $\begin{array}{c}-0.066^{* * *} \\
(-5.55)\end{array}$ & & \\
\hline or $\quad$ Bank $\_2_{j, t T} \times \log I G V_{j t}$ & & & $\begin{array}{c}0.039^{* * *} \\
(4.61)\end{array}$ & $\begin{array}{c}0.040^{* * *} \\
(4.48)\end{array}$ \\
\hline Observations (1993-98, 1999-2004) & $64(25,39)$ & $52(19,33)$ & $64(25,39)$ & $52(19,33)$ \\
\hline Correlation between subperiod residuals & -0.15 & -0.21 & 0.03 & 0.03 \\
\hline Adj. $R$-squared, (1993-98, 1999-2004) & $0.59,0.58$ & $0.60,0.60$ & $0.61,0.46$ & $0.61,0.45$ \\
\hline
\end{tabular}

Notes: $t$-statistics in parentheses. $*(* *, * * *)$ : significance at $10,(5,1)$ per cent. Instruments: one year lagged initial relative product varieties. Interval dummies not reported. The small country sample excludes observations from the six G-7 economies in our sample, i.e. the US, the UK, France, Germany, Italy and Canada (cf. fn. 6 in the text).We cannot reject non-normality of second subperiod residuals in $(5,6)$ on a Jarque-Bera test at 5 per cent level; qualitative results in $(5,6)$ are robust to removal of an outlier (YUG) normalising residuals, except for a substantial decline in the estimated speed of convergence. 
Table 3: Product variety growth regressions with banking reform in transition (3SLS): alternative microstate measures

Dependent variable: Average yearly growth rates of product variety in available capital goods relative to available consumer goods variety, $\left(\log C G V_{j, t+T}-\log C G V_{j t}\right) / T$

\begin{tabular}{|c|c|c|c|}
\hline & (3) & (7) & $(8)$ \\
\hline \multicolumn{4}{|l|}{ Explanatory variables: } \\
\hline $\begin{array}{l}\text { Initial variety relative to consumer } \\
\text { goods, } \log C G V_{j t}\end{array}$ & $\begin{array}{c}-0.028^{* * *} \\
(-3.24)\end{array}$ & $\begin{array}{l}-0.022^{* *} \\
(-2.36)\end{array}$ & $\begin{array}{c}-0.026^{* * *} \\
(-2.76)\end{array}$ \\
\hline $\begin{array}{l}\text { Average years of schooling, } \\
\qquad u 25 f_{j, t T}\end{array}$ & $\begin{array}{l}0.0012^{* *} \\
(2.07)\end{array}$ & $\begin{array}{l}0.0013^{* *} \\
(2.11)\end{array}$ & $\begin{array}{c}0.0012^{* *} \\
(0.98)\end{array}$ \\
\hline $\begin{array}{l}\text { Microstate, } \\
\qquad \text { Micro } 1 \times \log C G V_{j t}\end{array}$ & $\begin{array}{l}0.020^{* * *} \\
(3.15)\end{array}$ & & \\
\hline Micro $2 \times \log C G V_{j t}$ & & $\begin{array}{l}0.010^{*} \\
(1.79)\end{array}$ & \\
\hline Micro3 $\times \log C G V_{j t}$ & & & $\begin{array}{l}0.012^{* *} \\
(2.30)\end{array}$ \\
\hline $\begin{array}{l}\text { Investment-consumption ratio change, } \\
\quad i n v \_c o n_{j, t+T}-i n v_{-} c o n_{j t}\end{array}$ & $\begin{array}{c}0.071^{* * *} \\
(4.57)\end{array}$ & $\begin{array}{c}0.076^{* * *} \\
(4.71)\end{array}$ & $\begin{array}{c}0.077^{* * *} \\
(4.86)\end{array}$ \\
\hline $\begin{array}{l}\text { Banking reform, } \\
\qquad \text { Bank } 2_{j, t T} \times \log C G V_{j t}\end{array}$ & $\begin{array}{l}-0.065^{* * *} \\
(-5.59)\end{array}$ & $\begin{array}{l}-0.064^{* * *} \\
(-5.28)\end{array}$ & $\begin{array}{c}-0.069^{* * *} \\
(-5.73)\end{array}$ \\
\hline Observations (1993-98, 1999-2004) & $64(25,39)$ & $64(25,39)$ & $64(25,39)$ \\
\hline Correlation between subperiod residuals & -0.15 & -0.14 & -0.19 \\
\hline Adj. $R$-squared, (1993-98, 1999-2004) & $0.59,0.58$ & $0.54,0.56$ & $0.58,0.54$ \\
\hline
\end{tabular}

Notes: $t$-statistics in parentheses. $*(* *, * * *)$ : significance at $10,(5,1)$ per cent. Instruments: one year lagged initial relative product varieties. Interval dummies not reported. 
Table 4: Product variety growth regressions with banking reform in transition (3SLS): alternative schooling measures

Dependent variable: Average yearly growth rates of product variety in available capital goods relative to available consumer goods variety, $\left(\log C G V_{j, t+T}-\log C G V_{j t}\right) / T$

\begin{tabular}{|c|c|c|c|c|}
\hline & (3) & (9) & (10) & (11) \\
\hline \multicolumn{5}{|l|}{ Explanatory variables: } \\
\hline $\begin{array}{l}\text { Initial variety relative to consumer } \\
\text { goods, } \log C G V_{j t}\end{array}$ & $\begin{array}{c}-0.028^{* * *} \\
(-3.24)\end{array}$ & $\begin{array}{c}-0.029^{* * *} \\
(-3.37)\end{array}$ & $\begin{array}{c}-0.030^{* * *} \\
(-3.35)\end{array}$ & $\begin{array}{c}-0.030^{* * *} \\
(-3.48)\end{array}$ \\
\hline $\begin{array}{l}\text { Average years of schooling, } \\
\qquad u 25 f_{j, t T}\end{array}$ & $\begin{array}{c}0.0012^{* *} \\
(2.07)\end{array}$ & & & \\
\hline$u 15 f_{j, t T}$ & & $\begin{array}{c}0.0013^{* *} \\
(2.10)\end{array}$ & & \\
\hline$u 25_{j, t T}$ & & & $\begin{array}{c}0.0011^{*} \\
(1.67)\end{array}$ & \\
\hline$u 15_{j, t T}$ & & & & $\begin{array}{c}0.0012^{*} \\
(1.73)\end{array}$ \\
\hline $\begin{array}{l}\text { Microstate, } \\
\qquad \text { Micro } 1 \times \log C G V_{j t}\end{array}$ & $\begin{array}{l}0.020^{* * *} \\
(3.15)\end{array}$ & $\begin{array}{l}0.017^{* *} \\
(2.36)\end{array}$ & $\begin{array}{c}0.020^{* * *} \\
(3.17)\end{array}$ & $\begin{array}{l}0.018^{* *} \\
(2.40)\end{array}$ \\
\hline $\begin{array}{l}\text { Investment-consumption ratio change, } \\
\text { inv_con }{ }_{j, t+T}-i n v_{c} c o n_{j t}\end{array}$ & $\begin{array}{l}0.071^{* * *} \\
(4.57)\end{array}$ & $\begin{array}{c}0.069^{* * *} \\
(4.41)\end{array}$ & $\begin{array}{c}0.073^{* * *} \\
(4.72)\end{array}$ & $\begin{array}{l}0.072^{* * *} \\
(4.57)\end{array}$ \\
\hline $\begin{array}{l}\text { Banking reform, } \\
\qquad \text { Bank_2 } 2_{j, t T} \times \log C G V_{j t}\end{array}$ & $\begin{array}{c}-0.065^{* * *} \\
(-5.59)\end{array}$ & $\begin{array}{c}-0.066^{* * *} \\
(-5.70)\end{array}$ & $\begin{array}{c}-0.064^{* * *} \\
(-5.46)\end{array}$ & $\begin{array}{c}-0.065^{* * *} \\
(-5.57)\end{array}$ \\
\hline Observations (1993-98, 1999-2004) & $64(25,39)$ & $62(24,38)$ & $64(25,39)$ & $62(24,38)$ \\
\hline Correlation between subperiod residuals & -0.15 & -0.15 & -0.13 & -0.13 \\
\hline Adj. $R$-squared, (1993-98, 1999-2004) & $0.59,0.58$ & $0.54,0.57$ & $0.57,0.57$ & $0.53,0.57$ \\
\hline
\end{tabular}

Notes: $t$-statistics in parentheses. $*(* *, * * *)$ : significance at $10,(5,1)$ per cent. Instruments: one year lagged initial relative product varieties. Interval dummies not reported. 
Table A1: Countries and country codes

\begin{tabular}{|c|c|c|c|c|c|c|c|c|}
\hline 1 & $A L B$ & Albania & 17 & GBR & United Kingdom & 33 & NLD & Netherlands \\
\hline 2 & $A R M$ & Armenia & 18 & $G E O$ & Georgia & 34 & NOR & Norway \\
\hline 3 & AUT & Austria & 19 & GER & Germany & 35 & $P O L$ & Poland \\
\hline 4 & $A Z E$ & Azerbaijan & 20 & GRC & Greece & 36 & PRT & Portugal \\
\hline 5 & BEL & $\begin{array}{l}\text { Belgium \& } \\
\text { Luxemburg }\end{array}$ & 21 & $H R V$ & Croatia & 37 & $R O M$ & Romania \\
\hline 6 & $B G R$ & Bulgaria & 22 & $H U N$ & Hungary & 38 & $R U S$ & Russia \\
\hline 7 & $B L R$ & Belarus & 23 & IRL & Ireland & 39 & $S V K$ & Slovakia \\
\hline 8 & CAN & Canada & 24 & ISL & Iceland & 40 & $S V N$ & Slovenia \\
\hline 9 & CHE & Switzerland & 25 & ITA & Italy & 41 & SWE & Sweden \\
\hline 10 & CYP & Cyprus & 26 & $K A Z$ & Kazakhstan & 42 & $T K M$ & Turkmenistan \\
\hline 11 & $C Z E$ & Czech Republic & 27 & $K G Z$ & Kyrgyzstan & 43 & TUR & Turkey \\
\hline 12 & DNK & Denmark & 28 & $L T U$ & Lithuania & 44 & $U K R$ & Ukraine \\
\hline 13 & ESP & Spain & 29 & $L V A$ & Latvia & 45 & USA & United States \\
\hline 14 & $E S T$ & Estonia & 30 & $M D A$ & Moldova & 46 & $Y U G$ & $\begin{array}{l}\text { Serbia and } \\
\text { Montenegro }\end{array}$ \\
\hline 15 & FIN & Finland & 31 & $M K D$ & Macedonia & & & \\
\hline 16 & FRA & France & 32 & MLT & Malta & & & \\
\hline
\end{tabular}

Note: Belgium and Luxembourg are treated as one country. Transition countries in italics. 


\section{Table A2: Ratio of reported exports (imports) of 3,121 basic headings to total exports (imports)}

Exports

\begin{tabular}{|c|c|c|c|c|c|c|c|c|c|c|c|c|c|}
\hline & 1992 & 1993 & 1994 & 1995 & 1996 & 1997 & 1998 & 1999 & 2000 & 2001 & 2002 & 2003 & 2004 \\
\hline ALB & & & & & 1.000 & 1.000 & 1.000 & 1.000 & 1.000 & 1.000 & 1.000 & 0.999 & 1.000 \\
\hline ARM & & & & & & 1.000 & & 1.000 & 0.970 & & 1.000 & 1.000 & 1.000 \\
\hline AUT & 0.990 & 0.991 & 1.000 & 0.935 & 0.954 & 0.932 & 0.937 & 0.949 & 0.951 & 0.953 & 0.950 & 0.957 & 0.958 \\
\hline AZE & & & & & 0.999 & 1.000 & 1.000 & 0.992 & 0.998 & 0.998 & 1.000 & 0.998 & 1.000 \\
\hline BEL & 0.980 & 0.979 & 0.979 & 1.000 & 0.996 & 0.996 & 0.954 & 0.961 & 0.965 & 0.969 & 0.967 & 0.973 & 0.975 \\
\hline BGR & & & & & 0.995 & 0.996 & 0.969 & 0.998 & 0.998 & 0.998 & 0.999 & 0.999 & 0.999 \\
\hline BLR & & & & & & & 0.992 & 0.995 & 0.996 & 0.994 & 0.966 & 0.967 & 0.971 \\
\hline CAN & 1.000 & 1.000 & 1.000 & 1.000 & 0.996 & 0.997 & 0.997 & 0.997 & 0.997 & 0.998 & 0.988 & 0.990 & 0.989 \\
\hline CHE & 1.000 & 1.000 & 1.000 & 1.000 & 0.999 & 0.999 & 0.999 & 0.999 & 0.999 & 0.999 & 0.981 & 0.987 & 0.986 \\
\hline CYP & 1.000 & 1.000 & 1.000 & 1.000 & 0.999 & 0.999 & 0.999 & 0.999 & 0.999 & 0.999 & 0.999 & 0.999 & 0.999 \\
\hline CZE & & 1.000 & 1.000 & 1.000 & 0.985 & 0.988 & 0.990 & 0.991 & 0.992 & 0.992 & 0.991 & 0.991 & 0.990 \\
\hline DNK & 1.000 & 1.000 & 1.000 & 1.000 & 0.999 & 1.000 & 1.000 & 1.000 & 1.000 & 1.000 & 0.998 & 0.998 & 0.998 \\
\hline ESP & 1.000 & 1.000 & 1.000 & 1.000 & 0.997 & 0.997 & 0.997 & 0.997 & 0.997 & 0.998 & 0.994 & 0.994 & 0.993 \\
\hline EST & & & & 0.968 & 1.000 & 1.000 & 0.999 & 0.998 & 1.000 & 1.000 & 0.998 & 0.997 & 0.999 \\
\hline FIN & 1.000 & 1.000 & 1.000 & 1.000 & 0.998 & 0.998 & 0.998 & 0.997 & 0.998 & 0.998 & 0.944 & 0.946 & 0.944 \\
\hline FRA & 0.982 & 0.999 & 0.974 & 0.973 & 0.993 & 0.973 & 0.974 & 0.977 & 0.977 & 0.978 & 0.974 & 0.974 & 0.974 \\
\hline GBR & 0.953 & 0.974 & 0.979 & 0.999 & 0.998 & 0.979 & 0.979 & 0.998 & 0.941 & 0.929 & 0.949 & 0.944 & 0.996 \\
\hline GEO & & & & & 1.000 & 1.000 & 0.999 & 1.000 & 1.000 & 1.000 & 1.000 & 1.000 & 1.000 \\
\hline GER & 0.991 & 0.991 & 0.989 & 0.989 & 0.988 & 0.988 & 0.989 & 0.992 & 0.994 & 0.994 & 0.988 & 0.989 & 0.990 \\
\hline GRC & 1.000 & 1.000 & 1.000 & 0.995 & 0.995 & 0.997 & 0.998 & 0.996 & 0.997 & 0.998 & 0.998 & 0.997 & 0.997 \\
\hline HRV & 1.000 & 1.000 & 1.000 & 1.000 & 1.000 & 1.000 & 1.000 & 1.000 & 1.000 & 1.000 & 0.997 & 0.997 & 0.998 \\
\hline HUN & 1.000 & 1.000 & 1.000 & 1.000 & 0.999 & 1.000 & 0.999 & 1.000 & 0.999 & 0.999 & 0.998 & 0.999 & 0.996 \\
\hline IRL & 0.996 & 0.993 & 0.994 & 0.990 & 0.997 & 0.998 & 0.996 & 0.997 & 0.997 & 0.997 & 0.991 & 0.989 & 0.996 \\
\hline ISL & 1.000 & 1.000 & 1.000 & 1.000 & 1.000 & 1.000 & 1.000 & 1.000 & 1.000 & 1.000 & 1.000 & 1.000 & 1.000 \\
\hline ITA & 1.000 & 1.000 & 1.000 & 1.000 & 0.998 & 0.998 & 0.998 & 0.998 & 0.998 & 0.998 & 0.996 & 0.996 & 0.981 \\
\hline KAZ & & & & 0.647 & 0.677 & 0.688 & 0.708 & 0.739 & 1.000 & 1.000 & & 0.999 & 0.786 \\
\hline KGZ & & & & 1.000 & 1.000 & & 0.349 & 0.793 & 1.000 & 1.000 & 1.000 & 0.999 & 0.999 \\
\hline LTU & & & 1.000 & 1.000 & 1.000 & 0.999 & 0.999 & 0.998 & 0.996 & 0.999 & 0.997 & 0.998 & 0.993 \\
\hline
\end{tabular}

Imports

$\begin{array}{lllllllllllll}1992 & 1993 & 1994 & 1995 & 1996 & 1997 & 1998 & 1999 & 2000 & 2001 & 2002 & 2003 & 2004\end{array}$

$\begin{array}{llllllllllllll}0.998 & 0.992 & 0.990 & 0.994 & 0.996 & 0.996 & 0.997 & 0.994 & 0.994\end{array}$

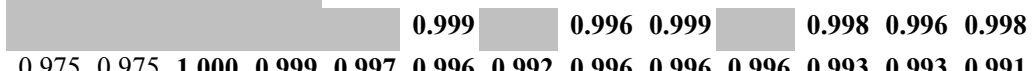
$\begin{array}{lllllllll}0.997 & 0.999 & 1.000 & 0.999 & 0.998 & 0.999 & 0.998 & 0.999 & 0.999\end{array}$ $\begin{array}{lllllllllllll}0.997 & 0.998 & 0.997 & 1.000 & 0.997 & 0.997 & 0.992 & 0.991 & 0.988 & 0.994 & 0.986 & 0.984 & 0.982\end{array}$ $\begin{array}{llllllllll}0.996 & 0.997 & 0.977 & 0.996 & 0.996 & 0.996 & 0.994 & 0.994 & 0.990\end{array}$ $\begin{array}{lllllll}\mathbf{0 . 9 9 5} & 0.997 & 0.997 & 0.997 & 0.935 & 0.945 & 0.951\end{array}$

$\begin{array}{lllllllllllll}1.000 & 1.000 & 1.000 & 1.000 & 0.999 & 0.998 & 0.999 & 0.999 & 0.999 & 0.999 & 0.996 & 0.996 & 0.996\end{array}$ $\begin{array}{llllllllllllll}1.000 & 1.000 & 1.000 & 1.000 & 0.998 & 0.997 & 0.997 & 0.998 & 0.997 & 0.998 & 0.988 & 0.988 & 0.992\end{array}$ $\begin{array}{lllllllllllll}1.000 & 1.000 & 1.000 & 1.000 & 0.998 & 0.998 & 0.998 & 0.999 & 0.998 & 0.999 & 0.996 & 0.996 & 0.996\end{array}$ $\begin{array}{llllllllllll}1.000 & 1.000 & 1.000 & 0.997 & 0.997 & 0.996 & 0.997 & 0.997 & 0.997 & 0.994 & 0.994 & 0.993\end{array}$ $\begin{array}{lllllllllllll}1.000 & 1.000 & 1.000 & 1.000 & 0.998 & 0.998 & 0.998 & 0.998 & 0.998 & 0.999 & 0.995 & 0.995 & 0.995\end{array}$ $\begin{array}{lllllllllllll}1.000 & 1.000 & 1.000 & 1.000 & 0.998 & 0.998 & 0.998 & 0.998 & 0.998 & 0.998 & 0.995 & 0.995 & 0.995\end{array}$ $\begin{array}{llllllllllll} & 0.991 & 0.999 & 0.999 & 0.997 & 0.994 & 0.998 & 0.999 & 0.996 & 0.996 & 0.996\end{array}$ $\begin{array}{llllllllllllll}1.000 & 1.000 & 1.000 & 1.000 & 0.998 & 0.999 & 0.998 & 0.999 & 0.999 & 0.999 & 0.997 & 0.997 & 0.997\end{array}$ $\begin{array}{llllllllllllll}1.000 & 1.000 & 0.999 & 0.999 & 0.997 & 0.997 & 0.996 & 0.997 & 0.997 & 0.998 & 0.992 & 0.993 & 0.993\end{array}$ $\begin{array}{lllllllllllll}0.978 & 0.997 & 0.997 & 0.999 & 0.998 & \mathbf{0 . 9 9 4} & \mathbf{0 . 9 9 4} & \mathbf{0 . 9 9 9} & 0.961 & 0.936 & 0.953 & 0.957 & \mathbf{0 . 9 9 4}\end{array}$ $\begin{array}{lllllllll}1.000 & 1.000 & 0.998 & 0.998 & 0.999 & 0.999 & 0.999 & 0.997 & 0.998\end{array}$ $\begin{array}{llllllllllllll}1.000 & 1.000 & 1.000 & 1.000 & 0.997 & 0.998 & 0.997 & 0.998 & 0.998 & 0.998 & 0.994 & 0.995 & 0.995\end{array}$ $\begin{array}{lllllllllllll}1.000 & 1.000 & 1.000 & 0.995 & 0.996 & 0.995 & 0.992 & 0.990 & 0.990 & 0.994 & 0.985 & 0.990 & 0.994\end{array}$ $\begin{array}{lllllllllllll}0.937 & 0.930 & 0.918 & 1.000 & 1.000 & 0.997 & 0.996 & 0.997 & 0.996 & 0.997 & 0.994 & 0.994 & 0.993\end{array}$ $\begin{array}{lllllllllllll}1.000 & 1.000 & 1.000 & 1.000 & 0.998 & 0.998 & 0.998 & 0.998 & 0.998 & 0.998 & 0.994 & 0.994 & 0.989\end{array}$ $\begin{array}{lllllllllllll}0.994 & 1.000 & 1.000 & 0.999 & 0.999 & 0.998 & 0.998 & 0.998 & 0.999 & 0.999 & 0.998 & 0.997 & 0.995\end{array}$ $\begin{array}{llllllllllllll}1.000 & 1.000 & 1.000 & 1.000 & 1.000 & 0.999 & 0.999 & 1.000 & 0.999 & 0.999 & 0.996 & 0.996 & 0.997\end{array}$ $\begin{array}{lllllllllllll}1.000 & 1.000 & 1.000 & 1.000 & 0.997 & 0.996 & 0.996 & 0.997 & 0.997 & 0.997 & 0.994 & 0.994 & 0.975\end{array}$ \begin{tabular}{|l|llllllllll}
\hline & 0.426 & 0.423 & 0.435 & 0.440 & 0.401 & 0.998 & 0.998 & & 0.995 & 0.399
\end{tabular} \begin{tabular}{ll|llllllll}
1.000 & 1.000 & & 0.399 & 0.403 & 0.997 & 0.996 & 0.996 & 0.993 & 0.993
\end{tabular} $\begin{array}{lllllllllll}1.000 & 1.000 & 1.000 & 0.997 & 0.997 & 0.997 & 0.995 & 0.998 & 0.994 & 0.994 & 0.989\end{array}$ 


\section{Table A2 contd.:}

Exports

\begin{tabular}{|c|c|c|c|c|c|c|c|c|c|c|c|c|c|c|c|c|c|c|c|c|c|c|c|c|c|c|}
\hline & 1992 & 1993 & 1994 & 1995 & 1996 & 1997 & 1998 & 1999 & 2000 & 2001 & 2002 & 2003 & 2004 & 1992 & 1993 & 1994 & 1995 & 1996 & 1997 & 1998 & 1999 & 2000 & 2001 & 2002 & 2003 & 2004 \\
\hline$\overline{\mathrm{LVA}}$ & & & 1.000 & 1.000 & 1.000 & 0.997 & 0.995 & 0.998 & 0.999 & 0.998 & 0.997 & 0.997 & 0.9 & & & 0.999 & 0.999 & 0.999 & 0.997 & 0.995 & 0.997 & 0.998 & 0.997 & 0.994 & 995 & 0.994 \\
\hline MDA & & & & 1.000 & 1.000 & 1.000 & 1.000 & 1.000 & 1.000 & 1.000 & 1.000 & 0.993 & 0.993 & & & & 1.000 & 1.000 & 1.000 & 1.000 & 1.000 & 0.999 & 0.999 & 0.999 & 0.998 & 0.995 \\
\hline MKD & & & 1.000 & 1.000 & 1.000 & 0.999 & 0.999 & 1.000 & 1.000 & 1.000 & 1.000 & 0.999 & 0.998 & & & 1.000 & 1.000 & 0.993 & 0.994 & 0.994 & 0.995 & 0.996 & 0.996 & 0.994 & 0.993 & 0.991 \\
\hline MLT & 1.000 & 1.000 & 1.000 & 1.000 & 1.000 & 1.000 & 1.000 & 0.999 & 0.999 & 0.999 & 1.000 & 0.999 & 1.000 & 1.000 & 1.000 & 1.000 & 1.000 & 0.997 & 0.997 & 0.996 & 0.997 & 0.998 & 0.997 & 0.995 & 0.991 & 0.986 \\
\hline NLD & 0.999 & 0.999 & 0.999 & 0.999 & 0.999 & 0.998 & 0.998 & 0.999 & 0.999 & 0.999 & 0.995 & 0.996 & 0.996 & 0.999 & 0.999 & 0.999 & 0.999 & 0.997 & 0.997 & 0.997 & 0.998 & 0.998 & 0.998 & 0.995 & 0.995 & 0.995 \\
\hline IOR & 0.977 & 1.000 & 1.000 & 1.000 & 0.999 & 0.999 & 0.999 & 0.999 & 1.000 & 1.000 & 0.994 & 0.994 & 0.995 & 0.998 & 1.000 & 1.000 & 1.000 & 0.999 & 0.999 & 0.999 & 0.999 & 0.999 & 0.999 & 0.996 & 0.997 & 0.997 \\
\hline POL & 0.978 & 0.983 & 1.000 & 1.000 & 0.993 & 0.994 & 0.997 & 0.996 & 0.996 & 0.997 & 0.997 & 0.997 & 0.996 & 0.978 & 0.985 & 1.000 & 1.000 & 0.995 & 0.999 & 0.998 & 0.998 & 0.998 & 0.998 & 0.992 & 0.992 & 0.991 \\
\hline PRT & 1.000 & 1.000 & 1.000 & 1.000 & 0.999 & 0.998 & 0.998 & 0.998 & 0.998 & 0.998 & 0.998 & 0.996 & 0.994 & 1.000 & 1.000 & 1.000 & 1.000 & 0.997 & 0.997 & 0.997 & 0.997 & 0.997 & 0.997 & 0.994 & 0.994 & 0.992 \\
\hline ROM & 0.996 & 1.000 & 1.000 & 1.000 & 1.000 & 0.981 & 0.988 & 0.995 & 0.997 & 0.998 & 0.998 & 0.998 & 0.996 & 0.999 & 1.000 & 1.000 & 1.000 & 1.000 & 0.999 & 0.999 & 0.999 & 0.999 & 0.999 & 0.995 & 0.995 & 0.995 \\
\hline RUS & & & & & 1.000 & 0.993 & 0.995 & 0.996 & 0.996 & 0.997 & 0.996 & 0.996 & 0.995 & & & & & 1.000 & 0.999 & 0.998 & 0.999 & 0.999 & 0.999 & 0.997 & 0.997 & 0.997 \\
\hline SVK & & & 1.000 & 1.000 & 1.000 & 0.996 & 0.996 & 0.997 & 0.997 & 0.997 & 0.997 & 0.997 & 0.996 & & & 1.000 & 1.000 & 1.000 & 0.995 & 0.995 & 0.996 & 0.997 & 0.997 & 0.992 & 0.992 & 0.991 \\
\hline SVN & 1.000 & 1.000 & & 1.000 & 0.999 & 0.999 & 0.999 & 0.999 & 0.999 & 0.999 & 0.989 & 0.990 & 0.989 & 1.000 & 1.000 & & 1.000 & 0.993 & 0.994 & 0.993 & 0.994 & 0.994 & 0.994 & 0.990 & 0.990 & 0.990 \\
\hline SWE & 0.999 & 0.999 & 0.999 & 0.999 & 0.997 & 0.997 & 0.997 & 0.997 & 0.997 & 0.998 & 0.984 & 0.986 & 0.987 & 1.000 & 1.000 & 1.000 & 0.999 & 0.997 & 0.997 & 0.997 & 0.997 & 0.997 & 0.998 & 0.996 & 0.995 & 0.995 \\
\hline TKM & & & & & & 0.981 & 0.983 & 1.000 & 1.000 & & & & & & & & & & 0.405 & 0.376 & 0.989 & 0.981 & & & & \\
\hline TUR & 1.000 & 1.000 & 0.978 & 0.982 & 0.983 & 0.992 & 0.981 & 0.986 & 0.982 & 0.981 & 0.982 & 1.000 & 1.000 & 1.000 & 1.000 & 0.989 & 0.973 & 0.976 & 0.997 & 0.961 & 0.943 & 0.957 & 0.950 & 0.959 & & \\
\hline UKR & & & & & 1.000 & 1.000 & 1.000 & 1.000 & 1.000 & 0.977 & 0.976 & & & & & & & 1.000 & 1.000 & 1.000 & 1.000 & 1.000 & 0.998 & 0.999 & & \\
\hline USA & 1.000 & 1.000 & 1.000 & 1.000 & 0.999 & 0.999 & 0.999 & 0.999 & 0.999 & 0.999 & 0.995 & 0.994 & 0.995 & 1.000 & 1.000 & 1.000 & 1.000 & 0.998 & 0.998 & 0.998 & 0.998 & 0.998 & 0.999 & 0.995 & 0.995 & 0.995 \\
\hline YUG & 1.000 & & & & 1.000 & 1.000 & 1.000 & 0.971 & 0.979 & 0.973 & 0.976 & & 0.995 & 1.000 & & & & 1.000 & 1.000 & 1.000 & 0.992 & 0.932 & 0.929 & 0.939 & & 0.987 \\
\hline
\end{tabular}

Notes: above 0.99, bold; below 0.90, red; no data,
Imports

$\begin{array}{lllllllllllll}28 & 28 & 31 & 36 & 43 & 44 & 45 & 46 & 46 & 44 & 44 & 42 & 43\end{array}$ 
Table A3: Variables used in the regressions, Tables 1-4

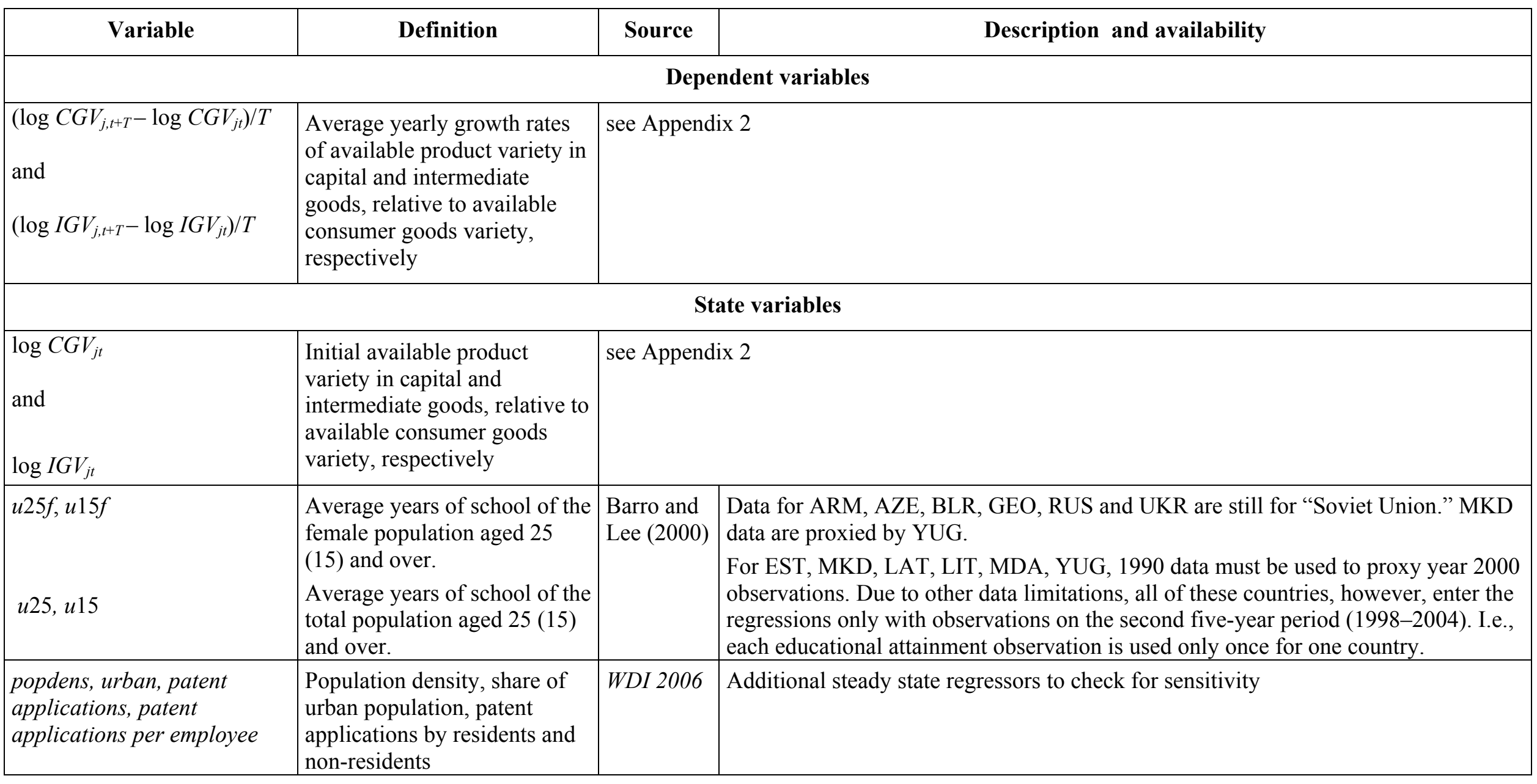


Table A3 contd.:

\begin{tabular}{|c|c|c|c|}
\hline Variable & Definition & Source & Description and availability \\
\hline$i n v_{-}{ }{ }^{\prime} n_{j, t+T}-i n v_{-} c o n_{j t}$ & $\begin{array}{l}\text { Change in investment- } \\
\text { consumption ratio }\end{array}$ & $\begin{array}{l}\text { calculated } \\
\text { from } W D I \\
2006 \text { data }\end{array}$ & Controls for specific demand effects on different BEC categories \\
\hline Micro1, Micro2, Micro3 & $\begin{array}{l}\text { Country dummies to control } \\
\text { for size effects on } \\
\text { specialisation - and thus } \\
\text { variety - patterns }\end{array}$ & $\begin{array}{l}\text { Own } \\
\text { definition }\end{array}$ & $\begin{array}{l}\text { Micro1: Population of less than } 1 \text { million (CYP, ISL, MLT), Micro2: Labour force } \\
\text { of less than } 1 \text { million (CYP, EST, ISL, MKD, MLT, SVN), Micro3: Labour force of } \\
\text { less than } 2 \text { million (ALB, ARM, CYP, EST, IRL, ISL, LTU. LVA, MKD, MLT, } \\
\text { SVN) }\end{array}$ \\
\hline Trans & $\begin{array}{l}\text { Country dummy to control for } \\
\text { transition effects }\end{array}$ & \multicolumn{2}{|c|}{ See Table A1 } \\
\hline $\begin{array}{l}L S P \_2, L S P \_3, R E F 1 \_2, \\
R e f 1 \_3, C G o v \_2 \text {, and Bank_2 }\end{array}$ & $\begin{array}{l}\text { Policy reform dummies in } \\
\text { transition economies, where } \\
\text { LSP: large scale privatisation, } \\
\text { Refl: first stage reforms, i.e., } \\
\text { liberalisation of prices and } \\
\text { foreign trade plus small and } \\
\text { large scale privatisation, } \\
\text { SGov: Governance and } \\
\text { enterprise restructuring, and } \\
\text { Bank: Banking reform and } \\
\text { interest rate liberalisation }\end{array}$ & EBRD & $\begin{array}{l}\text { EBRD transition indicators are measured on a scale between } 1 \text { and } 4+(=4.33) \text {. } \\
\text { According to the EBRD, } 1 \text { represents no or little progress; } 2 \text { indicates important } \\
\text { progress; } 3 \text { is substantial progress; } 4 \text { indicates comprehensive progress, while } 4+ \\
\text { indicates countries have reached the standards and performance norms of advanced } \\
\text { industrial countries. Accordingly, the competition policy of all non-transition } \\
\text { countries in the sample is evaluated at } 4+\text {. } \\
\text { Dummy variables from the EBRD measures indicate whether or not a country has } \\
\text { made the step towards a certain level in the EBRD scale on the respective policy area } \\
\text { within a given period. } \\
\text { Acknowledging that reform progress in different fields has been of different speed, } \\
\text { we define six such measures and interact them with the speed of convergence. }\end{array}$ \\
\hline
\end{tabular}


Table A4: List of countries in regression samples in Tables 1-4

\begin{tabular}{|c|c|c|}
\hline Columns 1, 2, 3, 5, 7, 8, 10 & Columns 4, 6 & Columns 9, 11 \\
\hline 1993-97 1998-2004 & 1993-97 1998-2004 & 1993-97 1998-2004 \\
\hline ALB & ALB & ALB \\
\hline AUT AUT & AUT AUT & AUT AUT \\
\hline AZE & AZE & AZE \\
\hline BEL BEL & BEL BEL & BEL BEL \\
\hline BGR & BGR & BGR \\
\hline BLR & BLR & BLR \\
\hline CAN CAN & CAN CAN & CAN CAN \\
\hline CHE CHE & CHE CHE & CHE CHE \\
\hline CYP & CYP & CYP \\
\hline $\mathrm{CZE}$ & $\mathrm{CZE}$ & $\mathrm{CZE}$ \\
\hline DNK DNK & DNK DNK & DNK DNK \\
\hline ESP ESP & ESP ESP & ESP ESP \\
\hline EST & EST & EST \\
\hline FIN FIN & FIN FIN & FIN FIN \\
\hline FRA FRA & & FRA FRA \\
\hline GBR GBR & & GBR GBR \\
\hline GEO & GEO & GEO \\
\hline GER GER & & GER GER \\
\hline GRC GRC & GRC GRC & GRC GRC \\
\hline HRV & HRV & HRV \\
\hline HUN HUN & HUN HUN & HUN HUN \\
\hline IRL IRL & IRL IRL & IRL IRL \\
\hline ISL ISL & ISL ISL & ISL ISL \\
\hline ITA ITA & ITA ITA & ITA ITA \\
\hline LTU & LTU & LTU \\
\hline LVA & LVA & LVA \\
\hline MDA & MDA & MDA \\
\hline MKD & MKD & MKD \\
\hline MLT MLT & MLT MLT & \\
\hline NLD NLD & NLD NLD & NLD NLD \\
\hline NOR NOR & NOR NOR & NOR NOR \\
\hline PRT PRT & PRT PRT & PRT PRT \\
\hline ROM ROM & ROM ROM & ROM ROM \\
\hline RUS & RUS & RUS \\
\hline SVK & SVK & SVK \\
\hline SVN SVN & SVN SVN & SVN SVN \\
\hline SWE SWE & SWE SWE & SWE SWE \\
\hline TUR TUR & TUR TUR & TUR TUR \\
\hline USA USA & & USA USA \\
\hline YUG & YUG & YUG \\
\hline
\end{tabular}

Notes: Columns refer to Tables 1-4. 